\title{
Desempenho de Novilhos Jovens e Superjovens de Diferentes Grupos Genéticos Terminados em Confinamento 1
}

\section{Paulo Santana Pacheco ${ }^{2}$, João Restle ${ }^{3}$, José Henrique Souza da Silva ${ }^{4}$, Ivan Luiz Brondani ${ }^{5}$, Leonir Luiz Pascoal ${ }^{6}$, Miguelangelo Ziegler Arboitte ${ }^{7}$, Aline Kellermann de Freitas ${ }^{8}$}

\begin{abstract}
RESUMO - O objetivo neste experimento foi avaliar o desempenho de novilhos dos grupos genéticos 5/8Charolês ( $\mathrm{CH}) 3 / 8 \mathrm{Nelore}(\mathrm{NE})$ e 5/8NE 3/8CH, pertencentes às categorias jovem e superjovem. A idade média dos animais ao final do período experimental foi de 22,8 meses para os jovens e de 15,2 meses para os superjovens. Os animais foram terminados em confinamento até atingirem peso de abate previamente estabelecido em $430 \mathrm{~kg}$. As características de desempenho avaliadas entre as categorias foram comparadas de duas formas: (=PF): até os superjovens atingirem peso final similar ao dos jovens; e (=ECF): até os superjovens atingirem estado corporal final (ECF) semelhante ao dos jovens. Foi utilizada relação volumoso:concentrado de 60:40 (base da matéria seca), com dieta contendo 10,25\% de proteína bruta e 3,18 Mcal de energia digestível $/ \mathrm{kg}$ de matéria seca. O delineamento experimental adotado foi o inteiramente casualizado, em arranjo fatorial $2 \mathrm{x}$ 2 (duas categorias $\mathrm{x}$ dois grupos genéticos). Novilhos jovens apresentaram maior ganho de peso médio diário (GMD) (1,94 kg) em relação aos superjovens $(=P F)(1,52 \mathrm{~kg})$ e (=ECF) $(1,53 \mathrm{~kg})$. Comportamento semelhante foi verificado para consumo de matéria seca (CMS) e de energia digestível, expressos por unidade de tamanho metabólico, consumo de energia líquida de mantença (ELm) e de ganho. Quando a ELm foi ajustada para $100 \mathrm{~kg}$, novilhos jovens apresentaram menores consumos em relação aos superjovens (=PF) e (=ECF). O ECF foi superior nos animais superjovens (=PF) (4,35 vs 3,72 pontos) em relação aos jovens. As conversões alimentar e energética apresentaram maiores valores para os jovens comparados com os superjovens (=ECF). Entre os grupos genéticos, não se verificou diferença para GMD. No entanto, animais 5/8NE 3/8CH apresentaram maior ECF e CMS em percentual do peso vivo e por unidade de tamanho metabólico.
\end{abstract}

Palavras-chave: Bos indicus, Bos taurus, Canchim, conversão alimentar, cruzamento, ganho compensatório

\section{Feedlot Performance of Steers and Young Steers of Different Genetic Groups}

\begin{abstract}
The objective of the experiment was to evaluate the performance of males of two categories, steers and young steers, from two genetic groups, $5 / 8 \mathrm{Charolais}(\mathrm{CH}) 3 / 8 \mathrm{Nelore}(\mathrm{NE})$ and $5 / 8 \mathrm{NE} 3 / 8 \mathrm{CH}$. The average age of the animals at the beginning of the experimental period was 22.8 months for steers and 15.2 months for young steers. The animals were feedlot finished to reach slaughter weight of $430 \mathrm{~kg}$, previously established. The performance characteristics evaluated between categories were compared in two manners: (=FW): until young steers reach final weight similar to steers; and (=FBCS): until young steers reach final body condition score (FBCS) similar to steers. The diet, roughage:concentrate ratio of 60:40 (dry matter basis), contained 10.25\% crude protein and 3.18 Mcal of digestible energy $/ \mathrm{kg}$ of dry matter. The experimental design used was the completely randomized, in a $2 \mathrm{x} 2$ (two categories $\mathrm{x}$ two genetic groups) factorial scheme. Steers showed higher average daily weight gain (ADG) $(1.94 \mathrm{~kg})$ in relation to young steers (=FW) $(1.52 \mathrm{~kg})$ and (=FBCS) $(1.53 \mathrm{~kg})$. Similar behavior was verified for dry matter intake (DMI) and digestible energy intake, expressed per unit of metabolic weight, net energy intake for maintenance (NEm) and for gain (NEg). When NEm was adjusted for $100 \mathrm{~kg}$ of body weight, steers showed lower intakes in relation to young steers $(=\mathrm{FW})$ and (=FBCS). The FBCS was higher in young steers (=FW) (4.35 vs. 3.72 points) in relation to steers. The feed and energy conversion showed higher values for steers when compared to young steers (=FBCS). No significant difference was observed between genetic groups for ADG. However, 5/8NE 3/8CH animals showed higher FBCS and DMI adjusted for body weight and per unit of metabolic weight.
\end{abstract}

Key Words: Bos indicus, Bos taurus, Canchim, compensatory gain, crossbreeding, feed conversion

\section{Introdução}

$\mathrm{Na}$ cadeia produtiva da carne bovina, gradualmente o país está conquistando espaço no mercado internacional com o aumento nas exportações. No entanto, este segmento ainda está longe de atingir e superar os índices produtivos dos demais países concorrentes que tradicionalmente atuam neste setor.

\footnotetext{
${ }^{1}$ Parte da Dissertação de Mestrado do primeiro autor - PPGZ-UFSM.

2 Zootecnista, MSc. Aluno de Doutorado do PPGCA-UFG. E.mail: pspacheco@pop.com.br

3 Eng. Agr., Professor Visitante CNPq - Departamento de Produção Animal - EV/UFG, Campus Samambaia, C.P. 131 - Goiânia - GO (jorestle@terra.com.br).

4 Engenheiro-Agrônomo, PhD. Professor Adjunto do Departamento de Zootecnia da UFSM.

${ }^{5}$ Zootecnista, Dr. Professor Adjunto do Departamento de Zootecnia da UFSM.

6 Zootecnista, MSc. Professor Assistente do Departamento de Zootecnia da UFSM.

7 Zootecnista, MSc. Professor do Departamento de Zootecnia da UFSM.

${ }^{8}$ Aluna de Mestrado do Programa de Pós-Graduação em Ciência Animal da UFG - Goiânia, GO. Bolsista do CNPq
} 
O cenário atual tem impulsionado o aumento de pesquisas visando gerar tecnologias para incrementar a eficiência produtiva e econômica nos sistemas de produção de bovinos de corte.

Até o início dos anos 90, praticamente toda carne de bovinos machos que chegava ao consumidor era originária de novilhos de três a cinco anos de idade, consistindo em um produto de baixa qualidade. Diante desta realidade, no sul do país, Restle (1998), Restle et al. (1999), Restle et al. (2000) e Restle \& Vaz (2003) demonstraram que a redução na idade de abate, aliada ao potencial genético dos animais, tem sido importante alternativa para produzir carne de maneira eficiente e com qualidade.

Neste processo, podem ser empregados o sistema dois anos (novilho jovem) e o sistema um ano (novilho superjovem). A terminação de novilhos para abate aos 20-24 meses (novilho jovem) é uma prática que já vem sendo utilizada com bons resultados no Brasil. A terminação desta categoria em confinamento tem como princípio o abate dos animais na entressafra, podendo o produtor obter preços melhores pelo seu produto, enquanto na produção do novilho superjovem, que pode ser comercializado para o abate em idade de 12 a 16 meses, esta prática consiste em reduzir os custos de produção, com melhor qualidade da carne, reconquistando uma parcela de consumidores que busca qualidade em sua alimentação (Restle et al., 1999; Restle et al., 2000). Este sistema é mais utilizado em países desenvolvidos, mas o potencial de produção no Brasil é promissor.

Aliado à redução da idade de abate, o cruzamento tem sido fator fundamental na intensificação do sistema de produção de bovinos de corte. Até o início dos anos 90, o genótipo utilizado na produção pecuária dependia muito da preferência do pecuarista. No entanto, com a redução da lucratividade da pecuária de corte e com a concorrência dos demais países produtores de carne bovina, o produtor passou a buscar genótipos mais adequados ao seu sistema de produção, que sejam mais eficientes em converter alimento consumido em ganho de peso e que atendam à demanda do mercado, principalmente no requisito qualidade de carcaça e de carne.

Embora um genótipo muito empregado nos sistemas intensivos de produção bovina no sul do Brasil seja o produto do cruzamento Charolês x Nelore não existem informações sobre qual seria a melhor proporção de sangue entre estas duas raças.
O objetivo neste experimento foi avaliar o desempenho de novilhos pertencentes às categorias jovem ou superjovem de diferentes grupos genéticos (5/8Charolês 3/8Nelore ou 5/8Nelore 3/8Charolês), terminados em confinamento até atingirem peso de abate próximo a $430 \mathrm{~kg}$.

\section{Material e Métodos}

O experimento foi conduzido no Setor de Bovinocultura de Corte do Departamento de Zootecnia da Universidade Federal de Santa Maria, em Santa Maria - RS, localizado na região fisiográfica Depressão Central, a $153 \mathrm{~m}$ de altitude, que, segundo classificação de Köppen, apresenta clima subtropical úmido (cfa) (Moreno, 1961).

Foram utilizados 24 novilhos castrados, de mesmo rebanho, dos grupos genéticos 5/8Charolês $(\mathrm{CH})$ $3 / 8 \mathrm{Nelore}(\mathrm{NE})$ ou $5 / 8 \mathrm{NE} 3 / 8 \mathrm{CH}$, pertencentes às categorias jovem (animais abatidos com 20 a 24 meses de idade) ou superjovem (animais abatidos com 12 a16 meses de idade). A idade média dos animais ao final do período experimental foi de 22,8 meses para os jovens e de 15,2 meses para os superjovens.

Todos os animais foram desmamados precocemente (média de 75 dias) e receberam, por 30 dias, alimentação volumosa e concentrada. Após este período, os novilhos superjovens foram manejados em pastagem nativa recebendo suplementação concentrada. Os animais jovens, por sua vez, foram manejados, no primeiro inverno, em pastagem cultivada de aveia (Avena strigosa) + azevém (Lollium multiflorum) com suplementação concentrada e no restante do período em pastagem nativa. A suplementação concentrada foi composta por $96 \%$ de farelo de trigo, $3 \%$ de calcário calcítico, $1 \%$ de sal comum $(\mathrm{NaCl})$ e foi fornecida em quantidade equivalente a $0,7 \%$ do peso vivo.

As características de desempenho avaliadas entre as categorias foram comparadas de duas maneiras: (=PF) até os animais superjovens atingirem peso final similar ao dos jovens; e $(=\mathrm{ECF})$ até os animais superjovens alcançarem estado corporal final semelhante aos dos jovens.

Os animais foram mantidos em boxes de confinamento (10 $\mathrm{m}^{2} /$ animal) com piso pavimentado, cocho de concreto coberto para fornecimento de alimentos e bebedouro com água à vontade regulada por bóia automática. 
Antecedendo o período experimental, os animais foram submetidos a um período de adaptação de 14 dias às instalações e à dieta experimental, quando foi realizado controle de endo e ectoparasitas com aplicação subcutânea de produto comercial à base de ivermectina, em dosagem recomendada pelo fabricante.

Durante o período de alimentação em confinamento, os animais foram alimentados à vontade duas vezes ao dia ( $8 \mathrm{~h} \mathrm{e} 17 \mathrm{~h}$ ). O volumoso foi distribuído no comedouro e sobre o mesmo colocouse o concentrado, realizando a mistura em seguida. $\mathrm{O}$ consumo voluntário da dieta foi registrado diariamente, realizando-se a pesagem da quantidade de alimento oferecido e das sobras de alimento do dia anterior. A oferta de alimento foi estipulada em $10 \%$ acima do consumo voluntário, sendo regulada de acordo com o consumo do dia anterior.

A dieta foi calculada segundo o NRC (1996), objetivando um ganho de peso médio diário de $1,6 \mathrm{~kg} /$ animal, estimando-se consumo de $2,5 \mathrm{~kg}$ de matéria seca (MS)/100 kg peso vivo (PV). Para todos os animais, foi utilizada relação volumoso:concentrado de 60:40 (base na MS), com dieta contendo 10,25\% de proteína bruta e $3,18 \mathrm{Mcal}$ de energia digestível $/ \mathrm{kg}$ de MS. A silagem de milho utilizada foi de alta qualidade, com $46,5 \%$ de grãos na massa ensilada. Os ingredientes e suas composições percentuais na dieta, baseados na MS, foram: silagem de milho $(60,00 \%)$, farelo de trigo $(28,24 \%)$, sorgo em grão $(10,07 \%)$, uréia (45-00-00) (0,17\%), calcário calcítico $(1,02 \%)$, sal comum $(\mathrm{NaCl})(0,48 \%)$ e ionóforo (Rumensin $\left.{ }^{\circledR}\right)$ $(0,0128 \%)$.

Foram coletadas amostras representativas dos componentes da dieta alimentar (concentrado e volumoso) no início da adaptação e semanalmente durante o período experimental. As amostras foram présecas em estufa de ventilação forçada a $55^{\circ} \mathrm{C}$, por 72 horas, para determinação do teor de matéria parcialmente seca, e, posteriormente, foram processadas em moinho tipo Willey com peneira de malha de um milímetro. Foram determinados os teores de MS e matéria orgânica, de proteína bruta $(\mathrm{PB})$, extrato etéreo (EE), fibra bruta (FB), extrativos não nitrogenados (ENN) e cinzas, segundo AOAC (1984); digestibilidade in vitro da matéria orgânica e da matéria seca, segundo Tilley \& Terry (1963); teores de fibra em detergente neutro (FDN), corrigida para cinzas e amido, e de fibra em detergente ácido (FDA), segundo Van Soest \& Wine (1967).
Para obtenção da concentração de nutrientes digestíveis totais (NDT), empregou-se a fórmula: $\operatorname{NDT}(\%)=-72,93+4,675 * \mathrm{FB}-1,28 * \mathrm{EE}+0,497 * \mathrm{~PB}$ - $0,044 *\left(\mathrm{FB}^{2}\right)-0,76 *\left(\mathrm{EE}^{2}\right)-0,039 * \mathrm{FB} * \mathrm{ENN}+$ $0,087 * \mathrm{EE} * \mathrm{ENN}-0,152 * \mathrm{EE} * \mathrm{~PB}+0,74 *\left(\mathrm{EE}^{2}\right)^{*} \mathrm{~PB}$, sugerida pela Latin American Tables of Feed Composition (1974). Os resultados estão apresentados na Tabela 1.

A energia digestível (ED) foi calculada segundo o NRC (1996), em que $1 \mathrm{~kg}$ NDT=4,4 Mcal de ED/kg de MS. Os consumos de energia líquida de mantença (ELm) e energia líquida de ganho (ELg) pelos animais foram estimados segundo equações propostas pelo NRC (1984): $\quad \mathrm{ELm}=0,077^{*} \mathrm{PV}^{0,75}$; $\mathrm{ELg}=0,0493 * \mathrm{PV}^{0,75 *}$ ganho de peso médio diário (GMD) ${ }^{1,097}$ para os animais da categoria superjovem; e ELg $=0,0437 * \mathrm{PV}^{0,75 * \mathrm{GMD}^{1,097}}$ para os animais da categoria jovem.

Os animais foram pesados individualmente, no início e no final do período experimental, após jejum de sólidos de 14 horas, e em períodos intermediários de 21 dias. Conforme os animais atingiam peso final próximo de $430 \mathrm{~kg}$, as pesagens ocorriam com maior frequiência. No momento das pesagens, os animais foram avaliados quanto à condição corporal, atribuindo-se valores de 1 a 5, em que: 1=muito magro; 2=magro; 3=médio; 4=gordo e 5=muito gordo, segundo Restle (1972).

O delineamento experimental foi o inteiramente casualizado, em arranjo fatorial 2 x 2 (duas categorias $\mathrm{x}$ dois grupos genéticos), com três repetições por tratamento, de modo que, para as variáveis relacionadas com consumos de MS, ED, ELm, ELg e conversões alimentar e energética, cada unidade experimental foi representada por um lote de dois animais. Para as demais variáveis, cada animal constituiu uma unidade experimental. Foram realizadas as análises de variância, aplicando-se os testes F e Tukey (este último quando a interação foi significativa a 5\%), por intermédio do programa estatístico SAS (1997). O modelo matemático adotado na análise de variância foi:

$$
\Upsilon_{\mathrm{ijk}}=\mu+\mathrm{GG}_{\mathrm{i}}+\mathrm{C}_{\mathrm{j}}+\left(\mathrm{GG}^{*} \mathrm{C}\right)_{\mathrm{ij}}+\varepsilon_{\mathrm{ijk}} \text {, }
$$

em que: $\Upsilon_{i j k}=$ variáveis dependentes; $\mu=$ média geral de todas as observações; $\mathrm{GG}_{i}=$ efeito do grupo genético de ordem $i$, sendo $1=5 / 8$ Charolês $3 / 8$ Nelore e $2=5 / 8$ Nelore $3 / 8$ Charolês; $C_{j}=$ efeito da categoria de ordem $j$, sendo $1=$ jovem e $2=$ superjovem; $\left(\mathrm{GG}^{*} \mathrm{C}\right)_{i j}=$ interação entre o i-ésimo grupo genético e a j-ésima categoria; $\varepsilon_{i j k}=$ erro aleatório residual, NID $\left(0, \sigma^{2}\right)$. 
Tabela 1 - Teores de matéria seca (MS), proteína bruta (PB), extrato etéreo (EE), fibra bruta (FB), extrativos não nitrogenados (ENN), cinzas, fibra em detergente neutro (FDN), fibra em detergente ácido (FDA), digestibilidade in vitro da matéria seca (DIVMS), digestibilidade in vitro da matéria orgânica (DIVMO) e nutrientes digestíveis totais (NDT) dos componentes da dieta

Table 1 - Contents of dry matter (DM), crude protein (CP), ether extract (EE), crude fiber (CF), nitrogen-free extracts (NFE), ashes, neutral detergent fiber (NDF), acid detergent fiber (ADF), "in vitro" dry matter digestibility (IVDMD), "in vitro" organic matter digestibility (IVOMD) and total digestible nutrients (TDN) of the diet components

\begin{tabular}{|c|c|c|c|}
\hline \multirow{2}{*}{$\begin{array}{l}\text { Teor } \\
\text { Content }\end{array}$} & \multicolumn{3}{|c|}{$\begin{array}{l}\text { Componente da dieta } \\
\text { Diet component }\end{array}$} \\
\hline & $\begin{array}{l}\text { Silagem de milho } \\
\text { Corn silage }\end{array}$ & $\begin{array}{l}\text { Farelo de trigo } \\
\text { Wheat bran }\end{array}$ & $\begin{array}{l}\text { Sorgo grão } \\
\text { Sorghum grain }\end{array}$ \\
\hline $\mathrm{MS}, \%$ & 39,05 & 91,80 & 92,22 \\
\hline $\begin{array}{l}D M \\
\mathrm{~PB}, \% \\
C P\end{array}$ & 6,21 & 16,13 & 6,93 \\
\hline $\begin{array}{l}\mathrm{EE}, \% \\
E E, \%\end{array}$ & 2,05 & 3,88 & 1,01 \\
\hline $\begin{array}{l}\mathrm{FB}, \% \\
\mathrm{CF}\end{array}$ & 22,41 & 9,97 & 1,42 \\
\hline $\begin{array}{l}\text { ENN, \% } \\
\text { NFE }\end{array}$ & 68,50 & 68,99 & 89,11 \\
\hline $\begin{array}{l}\text { Cinzas, \% } \\
\text { Ashes }\end{array}$ & 1,24 & 1,64 & 1,85 \\
\hline $\begin{array}{l}\mathrm{FDN}^{1}, \% \\
N D F\end{array}$ & 39,03 & 37,45 & 17,98 \\
\hline $\begin{array}{l}\mathrm{FDN}^{2}, \% \\
N D F\end{array}$ & 45,56 & 37,72 & 32,10 \\
\hline $\begin{array}{l}\text { FDA, } \% \\
A D F\end{array}$ & 22,27 & 12,53 & 3,63 \\
\hline $\begin{array}{l}\text { DIVMS, \% } \\
\text { IVDMD }\end{array}$ & 58,64 & 70,31 & 81,14 \\
\hline $\begin{array}{l}\text { DIVMO, \% } \\
\text { IVOMD }\end{array}$ & 59,11 & 70,34 & 81,52 \\
\hline $\begin{array}{l}\text { NDT, } \% \\
T D N\end{array}$ & 69,32 & 76,02 & 80,37 \\
\hline
\end{tabular}

${ }_{1}^{1}$ Corrigido para cinzas e amido.

1 Corrected for ashes and starch.

${ }^{2}$ Não corrigido para cinzas e amido.

${ }^{2}$ Not corrected for ashes and starch.

Os dados foram testados quanto à normalidade, por meio do teste de Shapiro-Wilk (SAS, 1997), efetuando-se, quando necessário, a transformação da raiz quadrada dos dados dos parâmetros.

\section{Resultados e Discussão}

O peso inicial diferiu entre as diferentes categorias, o que era esperado em razão das diferenças de idade dos animais (Tabela 2). A diferença entre jovens e superjovens foi de $146,7 \mathrm{~kg}(365,2 \mathrm{vs} 218,5 \mathrm{~kg}$, respectivamente). Ressalta-se que, para os animais superjovens, o peso inicial é adequado quando se busca a terminação de novilhos desta categoria (Restle et al., 1999; Restle \& Vaz, 2003).

Entre categorias e grupos genéticos, ocorreram diferentes períodos de confinamento, como reflexo das diferenças verificadas no ganho de peso médio diário dos animais. Para os animais da categoria jovem, foram necessários 30 dias de terminação nos 5/8NE 3/8CH e 39 dias nos 5/8CH 3/8NE (Tabela 2). Além do elevado ganho de peso verificado, destacase também a vantagem de maiores pesos no início da fase de terminação para esta categoria (média de $365,2 \mathrm{~kg}$ ), necessitando ganhar somente $66,2 \mathrm{~kg}$ para atingir o peso de abate próximo ao estabelecido.

Com a redução gradual na margem de lucro no sistema de terminação, seja em pastagem, semiconfinamento ou confinamento, em virtude principalmente do incremento nos custos dos insumos, equipamentos e matéria-prima para confecção das dietas, cada vez mais períodos curtos de alimentação surgem como importante alternativa na redução dos custos de produção. Isto porque o animal que inicia o 
confinamento com peso elevado permanecerá neste até atingir acabamento mínimo, o que gera maior giro de capital e, dependendo da disponibilidade de animais para reposição, maior número de animais terminados. Estudando diferentes pesos ao início do período de terminação em confinamento (355 ou $450 \mathrm{~kg}$ ) de novilhos jovens 5/8NE $3 / 8 \mathrm{CH}$, alimentados até atingirem peso final próximo a $510 \mathrm{~kg}$, Restle et al. (2003) verificaram que aqueles confinados com $450 \mathrm{~kg}$ permaneceram menor tempo em confinamento (30 vs 94 dias) e apresentaram carcaças com espessura de gordura mínima exigida pelos frigoríficos (3,08 vs $7,33 \mathrm{~mm}$ ), rendimento de carcaça similar (Peixoto et al., 2003), e maiores percentuais de traseiro e de músculo na carcaça (Bernardes et al., 2003).

Analisando os períodos de confinamento entre os animais superjovens, verifica-se que para atingir grau de acabamento similar aos jovens, foram necessários 84 dias de alimentação contra 143 dias para que atingisse peso final similar aos jovens, diferença de 59 dias ou $70 \%$ na redução do período de terminação.

Considerando o rendimento de carcaça quente $(55,81 \%)$ apresentado pelos animais superjovens (Pacheco et al., 2005), estes apresentariam peso de carcaça quente de $193,55 \mathrm{~kg}$ (peso final de $346,8 \mathrm{~kg}$ ), que é aceitável para os frigoríficos da região sul do país para esta categoria, podendo ser comercializados sem prejuízo para o produtor.

Verifica-se na Tabela 2 o expressivo ganho de peso médio diário apresentado pelos animais da categoria jovem $(1,94 \mathrm{~kg} / \mathrm{dia})$ em relação aos superjovens, com similar peso final (1,52 kg/dia) ou estado corporal final $(1,53 \mathrm{~kg} / \mathrm{dia})$, sendo que, para estas duas últimas categorias, o ganho obtido foi muito próximo ao preconizado previamente $(1,6 \mathrm{~kg} / \mathrm{dia})$. Conforme extensa revisão realizada por Restle \& Vaz (2003), que avaliaram a eficiência de produção de novilhos jovens e superjovens, não se esperam grandes diferenças no ganho de peso médio diário entre estas categorias.

Mesmo com o período de adaptação de 14 dias, os expressivos ganhos de peso alcançados pelos novilhos da categoria jovem evidenciam a manifestação do ganho compensatório. O ganho compensatório é definido como a taxa de crescimento (mudança no peso vivo, $\mathrm{kg} / \mathrm{dia}$ ) exibida por um animal alimentado à vontade após período de estresse nutricional significativamente maior que a de um animal geneticamente similar, nas mesmas condições ambientais e de mesmo peso corporal, em crescimento normal (Hogg, 1991). O estresse nutricional refere-se à limitação alimentar quantitativa ou qualitativa que não permita ao animal expressar seu potencial genético de crescimento.

Além disso, se os animais da categoria jovem não tivessem sofrido restrição alimentar durante a fase de recria, teriam sido abatidos em menor idade. Contudo, é difícil predizer com exatidão que tipo de restrição (quantitativa ou qualitativa) ocorreu a estes animais, uma vez que não houve acompanhamento da evolução do peso durante o período pré-experimental.

Entre os grupos genéticos, não se verificou diferença para o ganho de peso médio diário, apesar da superioridade numérica de $19,2 \%$ para os novilhos com maior predominância de Nelore (2,11 vs $1,77 \mathrm{~kg}$ / dia). Provavelmente, o estresse nutricional destes animais foi maior no período pré-experimental, pois, segundo revisão de Benschop (2000), quanto maior a severidade da restrição alimentar, maiores ganhos de peso imediatamente após o período de realimentação são esperados. Bail et al. (2000), que avaliaram o desempenho em confinamento de novilhos cruzas Charolês e Nelore, com média de 20 meses de idade, mantidos na fase de recria em pastagem nativa ou cultivada, verificaram que o ganho de peso médio diário dos novilhos provenientes da pastagem nativa foi $20 \%$ superior ao daqueles da pastagem cultivada (1,30 vs $1,08 \mathrm{~kg})$.

Os resultados referentes ao estado corporal e ganho em estado corporal dos animais, de acordo com a categoria e o grupo genético, são apresentados na Tabela 3.

Ao início do período experimental, animais da categoria jovem apresentaram maior estado corporal inicial (2,95 pontos) quando comparados aos da categoria superjovem $(2,81$ pontos). No entanto, ambos os valores estão abaixo do estado médio, ou seja, com pouca deposição de gordura, indicando que os novilhos jovens apresentavam, ao início do período experimental, maior expressão muscular que os novilhos superjovens e que estes últimos estavam em franco desenvolvimento.

Porém, os resultados inverteram-se quando avaliado o estado corporal final, que foi superior nos animais superjovens (=PF) (4,35 vs 3,72 pontos). Este resultado é explicado pelo maior ganho em estado corporal total (1,54 vs 0,78 pontos), associado ao maior período de alimentação, alterando a composição do ganho de peso, ou seja, maior acúmulo de gordura em relação à deposição muscular.

Com relação aos grupos genéticos, animais 5/8NE 
Tabela 2 - Médias para período de confinamento, peso inicial, peso final e ganho de peso médio diário, de acordo com a categoria e o grupo genético

Table 2 - Means for confinement period, initial weight, final weight and average daily weight gain, according to category and genetic group

\begin{tabular}{|c|c|c|c|c|c|}
\hline \multirow{2}{*}{$\begin{array}{l}\text { Grupo genético } \\
\text { Genetic group }\end{array}$} & \multicolumn{5}{|c|}{$\begin{array}{l}\text { Categoria } \\
\text { Category }\end{array}$} \\
\hline & $\begin{array}{c}\text { Jovem } \\
\text { Steer }\end{array}$ & $\begin{array}{l}\text { Superjovem }(=\mathrm{PF})^{1} \\
\text { Young steer }(=F W)^{1}\end{array}$ & $\begin{array}{l}\text { Média * } \\
\text { Mean * }\end{array}$ & $\begin{array}{l}\text { Superjovem }(=\mathrm{ECF})^{2} \\
\text { Young steer }(=F B C S)^{2}\end{array}$ & $\begin{array}{l}\text { Média ** } \\
\text { Mean ** }\end{array}$ \\
\hline \multirow{4}{*}{$\begin{array}{l}5 / 8 \mathrm{CH} 3 / 8 \mathrm{NE} \\
5 / 8 \mathrm{NE} 3 / 8 \mathrm{CH}\end{array}$} & \multicolumn{5}{|c|}{$\begin{array}{l}\text { Período de confinamento, dias \# } \\
\text { Confinement period, days }\end{array}$} \\
\hline & 39 & 136 & - & 84 & - \\
\hline & 30 & 149 & - & 84 & - \\
\hline & \multicolumn{5}{|c|}{$\begin{array}{l}\text { Peso inicial, } \mathrm{kg} \\
\text { Initial weight, } \mathrm{kg}\end{array}$} \\
\hline \multirow{5}{*}{$\begin{array}{l}5 / 8 \mathrm{CH} 3 / 8 \mathrm{NE} \\
5 / 8 \mathrm{NE} 3 / 8 \mathrm{CH} \\
\text { Média (Mean) } \\
\mathrm{CV}, \%\end{array}$} & 368,0 & 219,3 & 293,7 & 219,3 & 293,7 \\
\hline & 362,3 & 218,7 & 290,0 & 218,7 & 290,0 \\
\hline & $365,2 \mathrm{Aa}$ & $218,5 \mathrm{~b}$ & & $218,5 \mathrm{~B}$ & \\
\hline & & & 12,05 & & 12,05 \\
\hline & & & $\begin{array}{l}\text { eso final, } \\
\text { nal weight, }\end{array}$ & & \\
\hline \multirow{5}{*}{$\begin{array}{l}\text { 5/8CH3/8NE } \\
5 / 8 \mathrm{NE} 3 / 8 \mathrm{CH} \\
\text { Média (Mean) } \\
\mathrm{CV}, \%\end{array}$} & 437,2 & 434,0 & 435,6 & 351,2 & 394,2 \\
\hline & 425,5 & 435,5 & 430,5 & 342,3 & 383,9 \\
\hline & $431,3 \mathrm{~A}$ & 434,8 & & $346,8 \mathrm{~B}$ & \\
\hline & \multicolumn{4}{|c|}{9,08} & 9,91 \\
\hline & \multicolumn{5}{|c|}{$\begin{array}{l}\text { Ganho de peso médio diário, } \mathrm{kg} \\
\text { Average daily weight gain, } \mathrm{kg}\end{array}$} \\
\hline $5 / 8 \mathrm{CH} 3 / 8 \mathrm{NE}$ & 1,77 & 1,58 & 1,68 & 1,57 & 1,67 \\
\hline 5/8NE $3 / 8 \mathrm{CH}$ & 2,11 & 1,46 & 1,78 & 1,48 & 1,79 \\
\hline Média (Mean) & $1,94 \mathrm{Aa}$ & $1,52 \mathrm{~b}$ & & $1,53 \mathrm{~B}$ & \\
\hline $\mathrm{CV}, \%$ & & & 20,86 & & 21,03 \\
\hline
\end{tabular}

\#Não analisado estatisticamente.

\# Not statistically analyzed.

CV - Coeficiente de variação, \% (Coefficient of variation, \%).

1 PF: até atingir peso final similar ao do jovem.

1 FW: until reaching similar final weight of steers.

2 ECF: até atingir estado corporal final similar ao do jovem.

2 FBCS: until reaching similar final body condition score of steers.

* Média para jovem e superjovem (=PF).

* Mean for steers and young steers (=FW).

** Média para jovem e superjovem (=ECF).

** Mean for steers and young steers (=FBCS).

a, b; A, B Médias seguidas por letras minúsculas ou maiúsculas distintas na linha, diferem pelo teste $F(P<0,05)$, entre jovem e superjovem (=PF) ou jovem e superjovem (=ECF), respectivamente.

a, $b ; A, B$ Means followed by different small or capital letters in the line, differ by $F$ test $(P<.05)$, between steers and young steers $(=F W)$ or steers and young steers $(=F B C S)$, respectively.

3/8CH apresentaram maior estado corporal final e ganho em estado corporal total que os 5/8CH 3/8NE, o que está associado à maior precocidade para deposição de gordura da raça Nelore, demonstrando marcante efeito genético aditivo para esta característica.

Na Tabela 4, estão apresentadas as médias referentes ao consumo diário de matéria seca, expresso em $\mathrm{kg} / \mathrm{dia}$, em percentual do peso vivo e por unidade de tamanho metabólico dos animais, de acordo com a categoria e o grupo genético. O consumo de matéria seca, expresso em $\mathrm{kg} / \mathrm{dia}$ apresentou interação significativa entre categoria e grupo genético. Maiores consumos foram verificados para os animais 5/8NE $3 / 8 \mathrm{CH}$ jovens $(10,47 \mathrm{~kg}) \mathrm{em}$ relação aos $5 / 8 \mathrm{CH} 3 / 8 \mathrm{NE}$ de mesma categoria $(8,77$ $\mathrm{kg}$ ) e ambos foram superiores aos animais superjovens $(7,22 \mathrm{~kg})$. 
Tabela 3 - Médias para estado corporal inicial e final, ganho em estado corporal total e ganho em estado corporal diário, de acordo com a categoria e o grupo genético

Table 3 - Means for initial and final body condition score, total body condition score gain and daily body condition score gain, according to category and genetic group



Na média, novilhos jovens consumiram $33,2 \%$ mais matéria seca $(\mathrm{kg} / \mathrm{dia})$ que os superjovens $(=\mathrm{PF})$ e $43,6 \%$ mais que os superjovens (=ECF), valores superiores aos relatados na revisão de Restle \& Vaz (2003), em que a redução foi, em média, de 19,35\% no consumo de matéria seca ( $\mathrm{kg} / \mathrm{dia})$, quando o sistema de terminação passou de dois para um ano. Além da elevada taxa de ganho de peso durante o período de realimentação, animais em ganho compensatório também apresentam aumento no consumo de alimentos (Ryan et al., 1993; NRC, 1996; Zubair \& Leeson, 1996, Hornick et al., 1998; Bail et al., 2000), o que parece lógico, para suportar as elevadas taxas de ganho de peso. A literatura cita valores de 5 a $17 \%$ de 
Tabela 4 - Médias para consumo diário de matéria seca em kg, em percentagem do peso vivo (\% PV) e em gramas por unidade de tamanho metabólico $\left(\mathrm{PV}^{0,75}\right)$, de acordo com a categoria e o grupo genético

Table 4 - Means for daily dry matter intake in $\mathrm{kg} /$ day, in percentage of live weight $(\% \mathrm{LW})$ and in grams per unit of metabolic weight (LW .75), according to category and genetic group

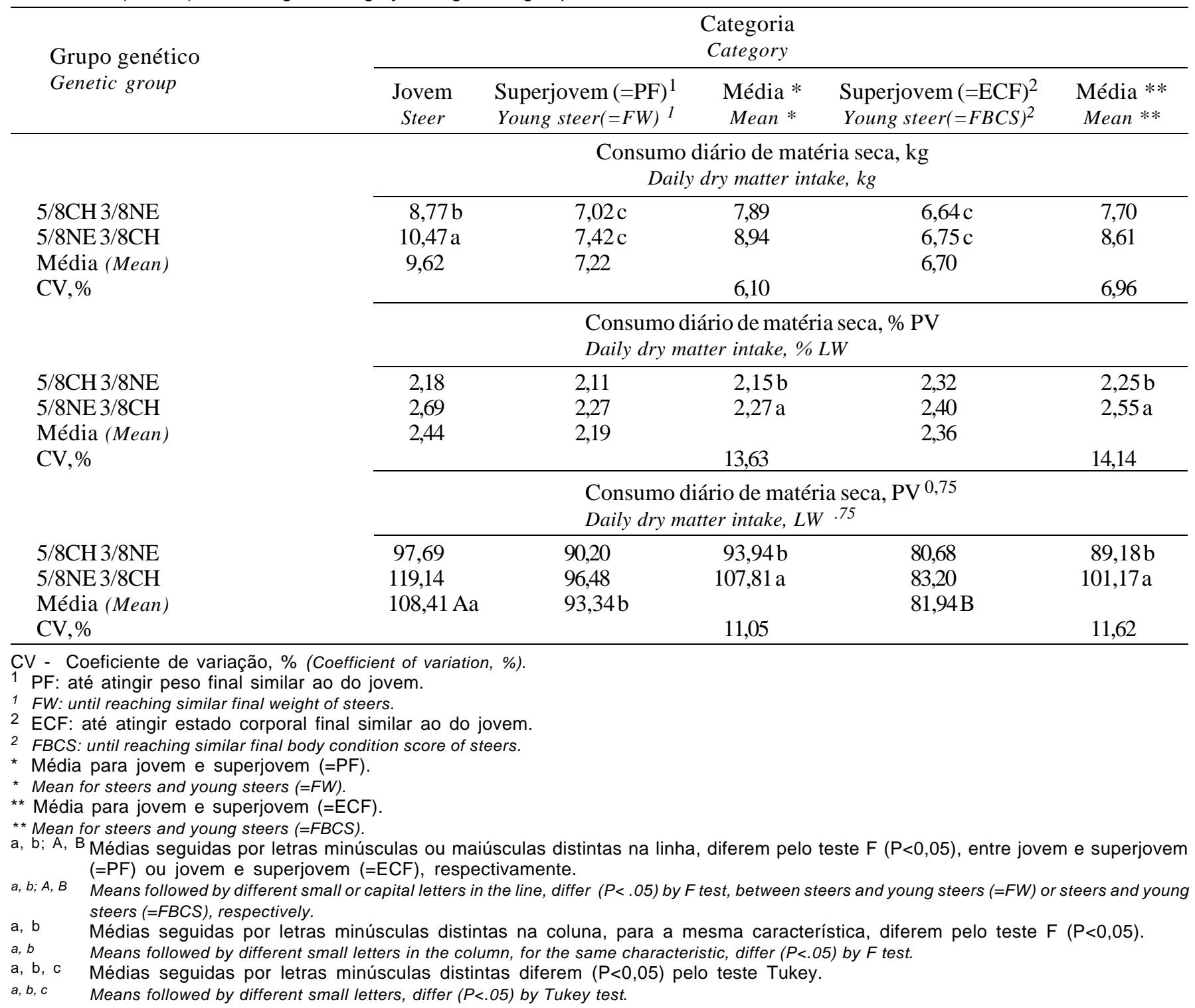

aumento no consumo de alimentos de bovinos em ganho compensatório em relação aos animais controle (Ryan et al., 1993; Santra \& Pathak, 1999).

Quando ajustado para $100 \mathrm{~kg}$ de peso vivo, não houve diferença significativa entre categorias. No entanto, comparando novilhos jovens com superjovens $(=\mathrm{PF})$, houve tendência de superioridade para os jovens $(\mathrm{P}=0,0815)$, tendência que se confirmou quando o consumo diário de matéria seca foi expresso por unidade de tamanho metabólico dos animais. Desta vez, animais da categoria jovem apresentaram maiores consumos $(108,41 \mathrm{~g})$ em relação aos superjovens (=PF) $(93,34 \mathrm{~g})$ e superjovens (=ECF) $(81,94 \mathrm{~g})$.
Avaliando o efeito de diferentes condições alimentares durante a fase de recria de novilhos de corte (pastagem nativa ou cultivada), no desempenho durante a fase de terminação, Bail et al. (2000) verificaram similaridade no consumo de matéria seca expressa em $\mathrm{kg} /$ dia $(8,55$ vs 8,45$)$ e superioridade para os animais que sofreram restrição alimentar na fase de recria, quando o consumo foi expresso por $100 \mathrm{~kg}$ de peso vivo $(2,48$ vs $2,17 \%)$. Os autores comentam ainda que os animais que permaneceram em pastagem nativa apresentaram restrição qualitativa e não quantitativa de forragem. Como a pastagem nativa apresenta maiores teores de fibra e menor digestibilidade que a pastagem 
Tabela 5 - Médias para consumo diário de energia digestível em Mcal, em percentagem do peso vivo (\% PV) e em kcal por unidade de tamanho metabólico $\left(\mathrm{PV}^{0,75}\right.$ ), consumo diário de energia líquida para mantença e para ganho, de acordo com a categoria e o grupo genético

Table 5 - Means for daily digestible energy intake in Mcal, in percentage of live weight (\% LW) and in Kcal per unit of metabolic weight $\left(L W{ }^{75}\right)$, daily net energy intake for maintenance and for gain, according to category and genetic group

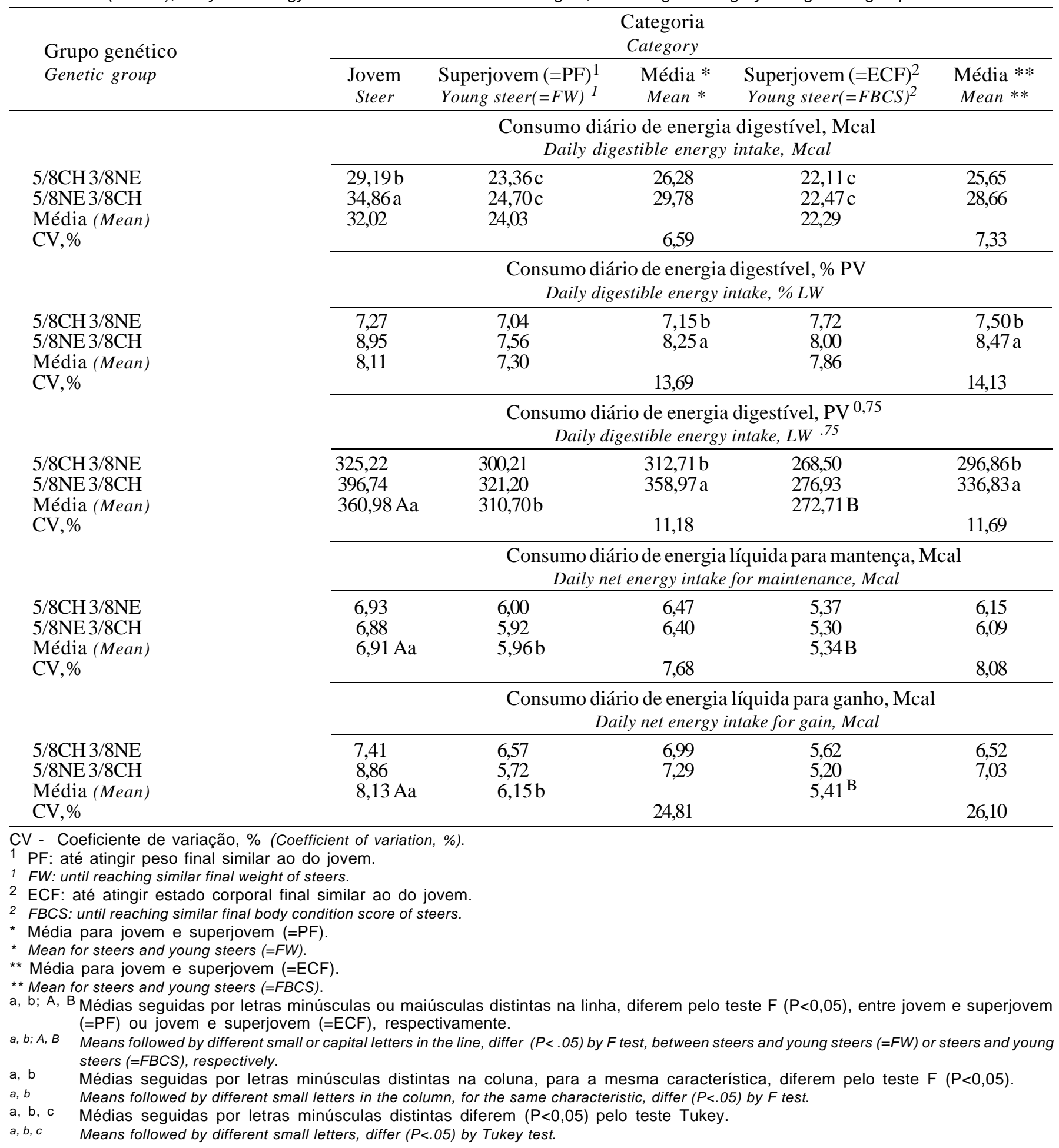

cultivada, os animais foram forçados a consumir mais matéria seca para atender suas exigências, resultando em maior desenvolvimento e capacidade do trato digestivo. Estes comentários podem ser válidos para os novilhos jovens do presente estudo, uma vez que, após o primeiro inverno, permaneceram o restante do período pré-experimental em pastagem nativa.

Analisando os grupos genéticos, verifica-se que novilhos com maior proporção de sangue Nelore no genótipo foram os que apresentaram maiores consu- 
Tabela 6 - Médias para conversão alimentar e energética, de acordo com a categoria e o grupo genético Table 6 - Means for feed and energetic conversion, according to category and genetic group

\begin{tabular}{|c|c|c|c|c|c|}
\hline \multirow{2}{*}{$\begin{array}{l}\text { Grupo genético } \\
\text { Genetic group }\end{array}$} & \multicolumn{5}{|c|}{$\begin{array}{l}\text { Categoria } \\
\text { Category }\end{array}$} \\
\hline & $\begin{array}{l}\text { Jovem } \\
\text { Steer }\end{array}$ & $\begin{array}{l}\text { Superjovem }(=\mathrm{PF})^{1} \\
\text { Young steer }(=F W)^{1}\end{array}$ & $\begin{array}{l}\text { Média* } \\
\text { Mean* }\end{array}$ & $\begin{array}{l}\text { Superjovem }(=\mathrm{ECF})^{2} \\
\text { Young steer }(=F B C S)^{2}\end{array}$ & $\begin{array}{l}\text { Média** } \\
\text { Mean** }\end{array}$ \\
\hline \multirow{4}{*}{$\begin{array}{l}\text { 5/8CH 3/8NE } \\
5 / 8 \mathrm{NE} 3 / 8 \mathrm{CH} \\
\text { Média (Mean) } \\
\mathrm{CV}, \%\end{array}$} & \multicolumn{5}{|c|}{$\begin{array}{c}\text { Conversão alimentar, } \mathrm{kg} \mathrm{MS} / \mathrm{kg} \text { ganho de peso } \\
\text { Feed conversion, } \mathrm{kg} \mathrm{DM/kg} \text { weight gain }\end{array}$} \\
\hline & 5,20 & 4,46 & 4,83 & 4,24 & 4,72 \\
\hline & $5,21 \mathrm{~A}$ & 4,78 & & $4,40 \mathrm{~B}$ & \\
\hline & & & 18,97 & & 19,54 \\
\hline & & $\begin{array}{r}\text { Conversão energ } \\
\text { Energetic con }\end{array}$ & $\begin{array}{l}\text { a, Mcal d } \\
\text { on, Mcal }\end{array}$ & $\begin{array}{l}\text { ED/kg ganho de peso } \\
\text { DE/kg weight gain }\end{array}$ & \\
\hline $\begin{array}{l}5 / 8 \mathrm{CH} 3 / 8 \mathrm{NE} \\
5 / 8 \mathrm{NE} 3 / 8 \mathrm{CH} \\
\text { Média (Mean) } \\
\mathrm{CV}, \%\end{array}$ & 17,28 & 14,85 & 16,07 & 14,13 & 15,71 \\
\hline \multicolumn{6}{|c|}{$\begin{array}{l}\text { CV - Coeficiente de variação, \% (Coefficient of variation, \%). } \\
1 \text { PF: até atingir peso final similar ao do jovem. } \\
1 \text { FW: until reaching similar final weight of steers. } \\
2 \text { ECF: até atingir estado corporal final similar ao do jovem. } \\
2 \text { FBCS: until reaching similar final body condition score of steers. } \\
\text { * Média para jovem e superjovem (=PF). } \\
\text { * Mean for steers and young steers (=FW). } \\
\text { ** Média para jovem e superjovem (=ECF). } \\
\text { ** Mean for steers and young steers (=FBCS). } \\
\text { a, b; A, B Médias seguidas por letras minúsculas ou maiúsculas distintas na linha, diferem pelo teste } \mathrm{F}(\mathrm{P}<0,05) \text {, entre jovem e superjovem } \\
\quad \text { (=PF) ou jovem e superjovem (=ECF), respectivamente. } \\
\begin{array}{l}\text { a, b; A, B Means followed by different small or capital letters in the line, differ }(P<.05) \text { by } F \text { test, between steers and young steers }(=F W) \text { or steers and young } \\
\quad \text { steers }(=F B C S), \text { respectively. }\end{array}\end{array}$} \\
\hline
\end{tabular}

mos de matéria seca em percentual do peso vivo e por unidade de tamanho metabólico, o que está de acordo com a superioridade numérica no ganho de peso médio diário (Tabela 2). De qualquer modo, seria esperado maior consumo para os animais com maior predominância de sangue Charolês, em razão de seu maior potencial produtivo e maiores exigências nutricionais (NRC, 1996). No entanto, quando os animais apresentam ganho compensatório, esta teoria não se valida, pois assim como o ganho de peso médio diário, o consumo de matéria seca também é diretamente influenciado pela severidade da restrição à que os animais foram submetidos, conforme Benschop (2000).

Na Tabela 5, estão apresentadas as médias relativas ao consumo de energia digestível e de energia líquida para mantença e ganho, de acordo com a categoria e o grupo genético. Para os consumos diários de energia digestível, expressos em Mcal, percentual do peso vivo e por unidade de tamanho metabólico dos animais, os resultados foram similares aos obtidos para os consumos diários de matéria seca (Tabela 4), tanto na comparação entre as categorias como entre os grupos genéticos. A relação foi direta, pois a dieta oferecida aos animais foi a mesma durante todo o período experimental.

Para o consumo diário de energia líquida de mantença, animais da categoria jovem apresentaram superioridade de $16 \%$ em relação aos superjovens (=PF) $(6,91$ vs 5,96 Mcal) e de $29,4 \%$ em relação aos superjovens (=ECF) (5,34 Mcal), resultado do maior peso dos animais jovens ao início do período de confinamento (Tabela 2), uma vez que a variação desta característica está relacionada diretamente ao peso vivo. Quando o consumo de energia líquida de mantença foi ajustado para $100 \mathrm{~kg}$ de peso vivo, houve diferenças entre as categorias $(\mathrm{P}=0,0001)$. Contudo, os resultados foram inversos aos verificados quando o consumo foi expresso em Mcal/dia, ou seja, menor para os animais jovens $(1,72 \%)$ que para superjovens $(=\mathrm{PF})(1,82 \%) \mathrm{e}$ superjovens $(=\mathrm{ECF})(1,88 \%)$. 
Diversos estudos demonstraram que a realimentação de animais após período de estresse nutricional promove redução das exigências de mantença dos animais (NRC, 1996; Benschop, 2000). Segundo revisão do NRC (1996), tem sido generalizada redução de $20 \%$ nos requerimentos de mantença, fato relacionado à alteração da taxa metabólica do animal. Ryan (1990) cita que a redução das exigências de mantença poderia então, permitir maior energia para crescimento durante a realimentação. No entanto, Benschop (2000) alerta que podem existir outros mecanismos ainda não compreendidos que são responsáveis pela redução das exigências de mantença dos animais em ganho compensatório.

Maiores consumos de energia líquida de ganho também foram verificados para os novilhos jovens (8,13 Mcal/dia) em relação aos superjovens (=PF) $(6,15 \mathrm{Mcal} / \mathrm{dia})$ e superjovens (=ECF) $(5,41 \mathrm{Mcal} /$ dia). A diferença percentual entre as categorias para esta característica, foi de 32,2 e 50,3\%, respectivamente. Valores estes superiores aos verificados para energia líquida de mantença, porque além do peso vivo dos animais, esta característica também apresenta relação direta com o ganho de peso vivo diário. No entanto, quando ajustado para $100 \mathrm{~kg}$ de peso vivo, o consumo de energia líquida de ganho não diferiu para nenhum dos efeitos estudados.

Os valores médios referentes às conversões alimentar e energética dos animais, de acordo com a categoria e o grupo genético, encontram-se na Tabela 6 .

A conversão alimentar e a conversão de energia foram similares entre os grupos genéticos estudados nas duas categorias. Entre as categorias jovem e superjovem (=PF), também houve similaridade para conversão alimentar $(5,21$ e 4,78) e para conversão de energia $(17,35$ e 15,90), indicando a grande eficiência da primeira categoria, quando em ganho compensatório. Outro fator indicativo da manifestação do ganho compensatório é a melhoria na eficiência alimentar dos animais (NRC, 1996; Bail et al., 2000; Benschop, 2000). Para a categoria jovem, as conversões alimentar e de energia verificadas foram muito aquém dos resultados observados por Restle \& Vaz (2003), envolvendo 12 estudos e 15 grupos genéticos diferentes, sendo os valores médios de 7,29 para conversão alimentar e 19,28 para conversão de energia, respectivamente.

Os animais jovens foram menos eficientes em transformar alimento consumido em ganho de peso $(5,21$ vs 4,40$)$ que os superjovens (=ECF) assim como foram menos eficientes em transformar energia consumida em ganho de peso $(17,35$ vs 14,65$)$, provavelmente em decorrência do menor ímpeto de deposição de gordura na fase inicial de alimentação dos superjovens $(=\mathrm{ECF})$, priorizando o crescimento muscular, que é um processo que exige menos energia por $\mathrm{kg}$ de incremento.

Na Tabela 7, são apresentados os valores médios referentes aos consumos totais de matéria seca, energia digestível, energia líquida de mantença e de ganho, explicados pelos diferentes períodos de confinamento entre as diferentes categorias e grupos genéticos, conforme apresentado na Tabela 2. Aplicando estes resultados no sistema de produção voltado para terminação de bovinos de corte em confinamento, a diferença individual no consumo total de matéria seca de $702,06 \mathrm{~kg}$ entre as categorias jovem e superjovem (=PF) $(327,95$ vs $1030,01 \mathrm{~kg})$, e de $234,5 \mathrm{~kg}$ entre as categorias jovem e superjovem (=ECF) $(327,95$ vs $562,45 \mathrm{~kg})$ poderia ser utilizada, teoricamente, para terminação adicional de 2,14 e 0,72 animais da categoria jovem, respectivamente. Assim como a diferença de 467,56 kg no consumo individual total de matéria seca entre os animais superjovens (=PF e =ECF) $(1030,01$ vs $562,45 \mathrm{~kg}$ ) poderia terminar 0,83 animal a mais se fossem alimentados até atingirem estado corporal final similar aos animais da categoria jovem.

Conclusões semelhantes referentes às vantagens que os curtos períodos de alimentação promovem em termos de aumento no total de animais terminados foram relatadas por Arboitte et al. (2004). Os autores verificaram que a quantidade de alimento gasto para terminar os novilhos mais pesados (abatidos com 510 $\mathrm{kg}$ ) seria suficiente para terminar 3,34 vezes mais novilhos com o peso mais leve (abatidos com $425 \mathrm{~kg}$ ), em período de tempo $68 \%$ mais curto.

\section{Conclusões}

Novilhos jovens apresentam maior desempenho, reflexo da manifestação do ganho compensatório. Considerando a diferença individual no consumo total de matéria seca entre jovens e superjovens com similar peso final, e entre jovens e superjovens com similar estado corporal final, poderiam ser terminados, adicionalmente, 2,14 e 0,72 animais da categoria jovem, respectivamente.

Novilhos superjovens são mais eficientes em converter matéria seca e energia digestível 
Tabela 7 - Médias para consumo total de matéria seca, energia digestível, energia líquida de mantença e energia líquida de ganho, de acordo com a categoria e grupo genético

Table 7 - Means for total intake of dry matter, digestible energy, net energy for maintenance and net energy for gain, according to category and genetic group

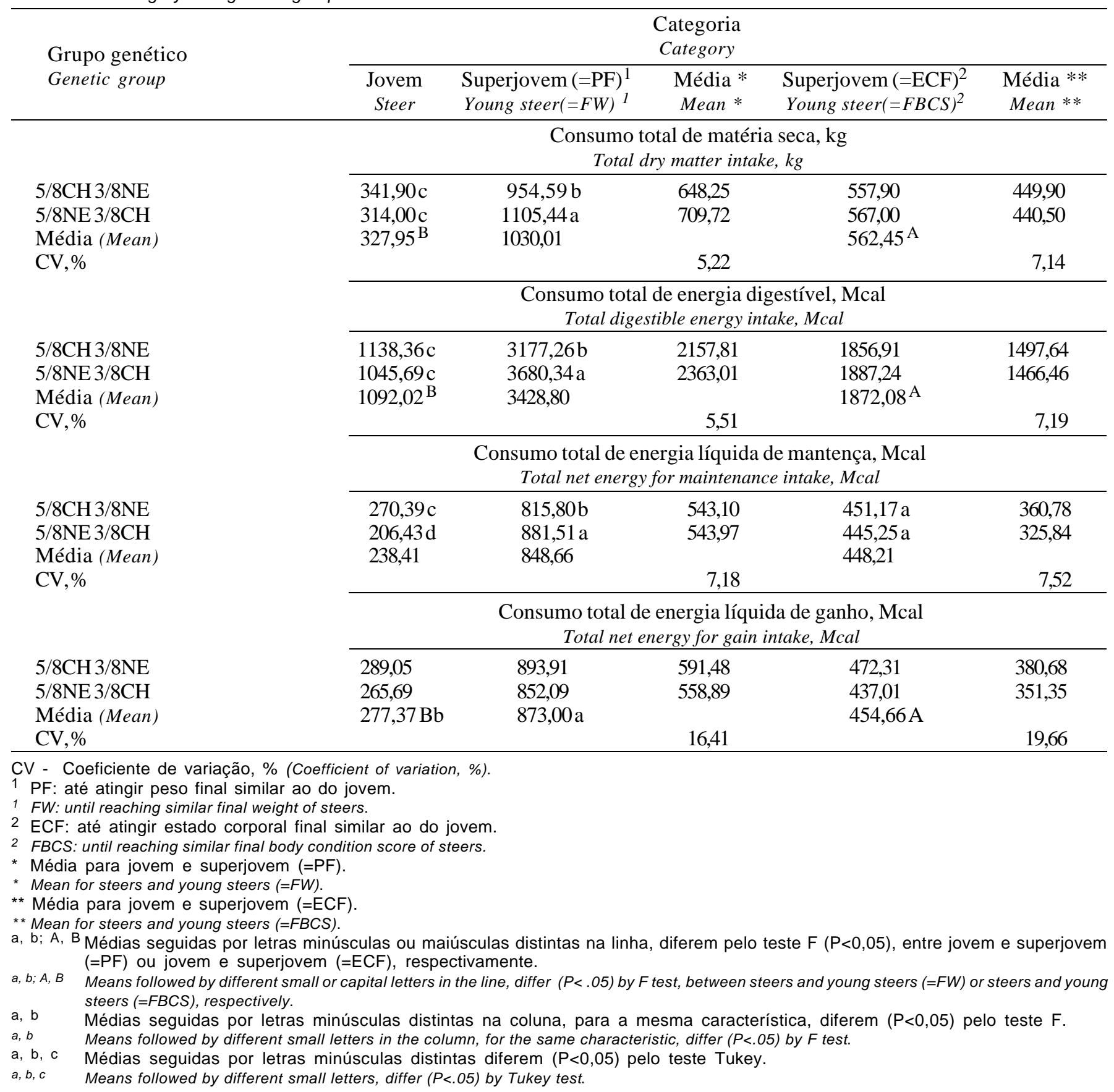

consumidas em ganho de peso quando alimentados até atingirem acabamento similar ao dos jovens e maior acabamento quando alimentados até atingirem peso final similar aos jovens.

Animais 5/8Nelore 3/8Charolês apresentam maior acabamento e desempenho similar aos 5/8Charolês 3/8Nelore durante a fase de terminação em confinamento.

\section{Literatura Citada}

ARBOITTE, M.Z.; RESTle, J.; ALVES FILHO, D.C. et al. Desempenho em confinamento de novilhos 5/8 Nelore - 3/ 8 Charolês, abatidos em diferentes estádios de desenvolvimento. Revista Brasileira de Zootecnia, v.33, n.4, p.947-958, 2004.

ASSOCIATION OF ANALITIC CHEMIST- AOAC. Official methods of analysis. 14.ed. Washington, D.C.: AOAC, 1984. 1141p. 
BAIL, C.A.T.; BRONDANI, I.L.; RESTLE, J. Níveis de concentrado na fase de terminação em confinamento para novilhos previamente mantidos em pastagem nativa ou cultivada. Ciência Rural, v.30, n.1, p.151-157, 2000.

BENSCHOP, D. Compensatory growth in ruminants - a overview. In: CANT, J. (Ed.) Proceedings of the 2000 Course in Ruminant Digestion and Metabolism - ANSC 6260. University of Guelph, 2000. p.1-16.

BERNARDES, R.A.C.; ALVES FILHO, D.C.; RESTLE, J. et al. Composição física e cortes comerciais da carcaça de novilhos com diferentes pesos ao início do confinamento, abatidos com $500 \mathrm{~kg}$. In: REUNIÃO ANUAL DA SOCIEDADE BRASILEIRA DE ZOOTECNIA, 40., 2003, Santa Maria. Anais... Santa Maria: SBZ [2003]. CD ROM. Nutrição de ruminantes.

HOGG, B.W. Compensatory growth in ruminants. In: Growth regulation in farm animal - advances in meat research. Corvallis Oregon: Elsevier, 1991. v.7, p.103-134.

HORNICK, J.L., Van EENAEME, C; CLINQUART, A. et al. Different periods of feed restriction before compensatory growth in Belgian Blue bulls: I. Animal performance, nitrogen balance, meat characteristics and fat composition. Journal of Animal Science, v.76, p.249-259, 1998.

LATIN AMERICAN TABLES OF FEED COMPOSITION. Florida: University of Florida, 1974. p.11-16.

MOREnO, J.A. Clima do Rio Grande do Sul. Porto Alegre: Secretaria da Agricultura, 1961. 41p.

NATIONAL RESEARCH COUNCIL - NRC. Nutrient requirements of domestic animals. 6.ed. Washington: National Academy Press, 1984. 90p.

NATIONAL RESEARCH COUNCIL - NRC. Nutrient requirements of domestic animals. 7.ed. Washington: National Academy Press, 1996. 242p.

PACHECO, P.S.; SILVA, J.H.S.; RESTLE, J. et al. Características da carcaça de novilhos jovens e superjovens de diferentes grupos genéticos. Revista Brasileira de Zootecnia, 2005 (no prelo).

PEIXOTO, L.A.O.; RESTLE, J.; ALVES FILHO, D.C. et al. Características quantitativas da carcaça de novilhos com diferentes pesos ao início do confinamento, abatidos com $500 \mathrm{~kg}$. In: REUNIÃO ANUAL DA SOCIEDADE BRASILEIRA DE ZOOTECNIA, 40., 2003, Santa Maria. Anais... Santa Maria: SBZ [2003]. CD ROM. Nutrição de ruminantes.

RESTLE, J. Comportamento reprodutivo do rebanho de gado de corte da fazenda experimental de criação experimental agronômica da UFRGS. $1^{\circ}$ Semestre, 1972. Seminário da disciplina de Técnicas de Pesquisa. Curso de Pós-Graduação em Agronomia, Universidade Federal do Rio Grande do Sul, 1972.
RESTLE, J. Produção do novilho superprecoce. In: RESTLE, J.; BRONDANI, I.L.; PASCOAL, L.L. et al. (Eds.) Produção intensiva com qualidade em bovinos de corte. Santa Maria: Universidade Federal de Santa Maria, 1998. p.58-70.

RESTLE, J.; ALVES FILHO, D.C.; NEUMANN, M. Eficiência na terminação de bovinos de corte. In: RESTLE, J. (Ed) Eficiência na produção de bovinos de corte. Santa Maria: Universidade Federal de Santa Maria, 2000. p.277-303.

RESTLE, J.; ALVES FILHO, D.C.; PASCOAL, L.L. et al. Terminação em confinamento de novilhos com diferentes pesos iniciais. In: REUNIÃO ANUAL DA SOCIEDADE BRASILEIRA DE ZOOTECNIA, 40., 2003, Santa Maria. Anais... Santa Maria: SBZ [2003]. CD ROM. Nutrição de ruminantes.

RESTLE, J.; BRONDANI, I.L.; BERNARDES, R.A.C. O novilho superprecoce. In: RESTLE, J. (Ed.) Confinamento, pastagens e suplementação para produção de bovinos de corte. Santa Maria: Universidade Federal de Santa Maria, 1999. p.191-214.

RESTLE, J.; VAZ, F.N. Eficiência e qualidade na produção de carne bovina. In: REUNIÃO ANUAL DA SOCIEDADE BRASILEIRA DE ZOOTECNIA, 40., 2003, Santa Maria. Anais... Santa Maria: Sociedade Brasileira de Zootecnia, 2003.

RYAN, W.J. Compensatory growth in cattle and sheep. Nutrition Abstracts and Reviews, v.60, p.653-664, 1990.

RYAN, W.J., WILLIAMS, I.H.; MOIR, R.J. Compensatory growth in sheep and cattle. I. Growth pattern and feed intake. Australian Journal of Agricultural Research, v.44, p.1623-1633, 1993.

SANTRA, A.; PATHAK, N.N. Nutrient utilization and compensatory growth in crossbred (Bos indicus $x$ Bos taurus) calves. Journal of Animal Science, v. 12, p.1285-1291, 1999.

STATISTICAL ANALYSES SYSTEMS - SAS. User's guide. Version 6, Cary: 1997. v.2, 1052p.

TILLEY, J.M.; TERRY, R.A. A two-stage technique for the in vitro digestion of forage crops. Journal of British Grassland Society, v.18, p.104-111, 1963.

Van SOEST, P.J.; WINE, R.H. Use of detergents in analysis of fibrous feeds. IV. Determinations of plant cell-wall constituents. Journal of the Association of Official Analysis Chemists, v.50, p.50, 1967.

ZUBAIR, A.K.; LEESON, S. Compensatory growth in the broiler chicken: a review. World Poultry Science, v.52, p.189-201, 1996.

Recebido em: 06/04/04 Aceito em: 23/11/04 